\title{
COMENTARIOS
}

\section{ADITIVOS ALIMENTARIOS: ¿QUÉ SON, CÓMO ACTÚAN, POR QUÉ SON TAN NECESARIOS?}

\author{
TERESA BLANCO DE ALVARADO-ORTIZ
}

FACULTAD DE MEDICINA HUMANA, UNIVERSIDAD DE SAN MARTÍN DE PORRES.

Para John M. deMan, en su obra Principles of Food Chemistry a los aditivos alimentarios con frecuencia se les asocia a algo químico, otorgándose erradamente a lo químico características de artificial, no siempre bueno para la salud. (1)

Dice bien erradamente, porque hombres, animales, plantas, microorganismos, alimentos, aire, cerros, minas y todo lo que nos rodea en la maravillosa naturaleza, es químico. Los aditivos alimentarios, todos químicos, naturales o artificiales son extraordinarias sustancias que otorgan mayor estabilidad a los alimentos, características agradables de olor, sabor, color, suavidad y que la industria utiliza en su fabricación, ya que sin ellos se correría grandes riesgo al consumir determinados alimentos.

Los aditivos seguros según el Comité Mixto $\mathrm{FAO} /$ OMS de Expertos en Aditivos Alimentarios JECFA son más de mil y de ellos la mayoría corresponde a pequeñísimas moléculas de estructura química sencilla, legisladas universal y rigurosamente y que constituyen un valioso apoyo a la alimentación y la salud(2).

Es poco frecuente asociar aditivos con alimentos aparentemente muy naturales como lo son los aceites vegetales, inclusive el de oliva, pan, mantequilla, bizcochos, purés instantáneos. Ellos se preparan utilizando ácidos, sales, álcalis, ésteres, para llegar a nosotros en la forma como nos gusta consumirlos, transparentes, con olor y sabor agradables, textura suave, larga vida en el mostrador, etc. Como en el rotulado sólo se indica lo que acompaña al alimento al momento de consumirlo y muchos aditivos ya no están presentes, fueron desapareciendo al cumplir con su función, pareciera que el alimento es muy natural.

\section{¿QUÉ SON LOS ADITIVOS ALIMENTARIOS?}

Son diversas sustancias químicas, naturales o sintetizadas en un laboratorio, agregadas intencionalmente a un alimento - sin propósito de nutrir - con el objetivo de modificar características físicas, químicas, biológicas durante su fabricación, tratamiento, embalaje, transporte, siempre para mejorarlo.

Respecto a los plaguicidas o pesticidas, aunque agregados intencionalmente, no son aditivos, cumplen otras funciones como evitar la acción devastadora de insectos y otros animales. Otras sustancias extrañas al alimento que tampoco son aditivos, son los contaminantes, presentes a veces en el alimento en ínfimas cantidades.

A Downham y P. Collins en el año 2000 publican en el International Journal of Food Science and Technology un extenso trabajo acerca de los colorantes que otorgan un color mejor o diferente al original o dan color al alimento que no lo tiene. (3)

Otros aditivos comúnmente empleados por la industria son los emulsionantes, estabilizantes y espesantes que mantienen la textura del alimento; los antioxidantes evitan oxidación o cambio de color; los saborizantes, mejoran el sabor al alimento insípido o bajo en sabor, aromatizantes, son flavorizantes, dan olor y sabor a plátano, naranja, melocotón, -sin esas frutas- a jugos, refrescos, mazamorras, pudines.

\section{¿A PARTIR DE CUÁNDO EL hOMBRE USA ADITIVOS EN SUS ALIMENTOS?}

Probablemente desde que se hizo sedentario y hoy gracias a la tecnología son más de mil y obtenidos industrialmente. Entre los primeros aditi- 
vos empleados por el hombre estaba la sal para preservar carnes y pescados; hojas, flores, pequeños tallos, peciolos, para mejorar el sabor, olor y color de sus comidas; azúcar para evitar deterioro de frutas y otros vegetales, vinagre obtenido por fermentación de uvas, para encurtidos.
Aditivos de origen $100 \%$ natural. Obtenidos de vegetales, animales o minerales. Son pocos los extraídos directamente sin modificaciones fabriles, como la sal que se extrae de salinas y de gemas. Necesita sólo purificación para ofrecerla pura y limpia. La industria aplica procedimientos mecánicos y físicos simples como limpieza, filtración,

\begin{tabular}{|lll|}
\hline Agente flavorizante & Mejorador de harina & Antihumectante \\
Espesante & Agente de firmeza & Secuestrante \\
Conservador & Emulsificante & Antiespumantes \\
Regulador de acidez & Glaceante & Diluente de colorante \\
Aromatizante & Espumante & Adsorbente \\
Gelificante & Fermento químico & Decolorante \\
Acidulante & Estabilizador de color & Antiaglutinante \\
Realzador de sabor & Realzador del sabor & Edulcorante \\
\hline
\end{tabular}

¿Cómo actúan los aditivos alimentarios? Según la FAO-WHO en su Norma General del Codex para Aditivos Alirnentarios Volumen 1A 1999, (4) los aditivos actúan como:

Los más empleados son colorantes beta caroteno y cochinilla; edulcorante aspartame; ácidos fosfórico, cítrico, acético, sulfúrico; aminoácido glutamato monosódico, sazonador más usado en el mundo; mentol, maltol, geraniol, vainillina, aromatizantes de dulces, bebidas y caramelos; glicerina y triglicéridos suavizantes para panificación; solventes orgánicos hexano, heptano; carbón, ceras, talco, nitritos y nitrato.

Su presencia como aditivos cobra sentido al conocer en qué alimentos se utilizan, como lo muestra la lista ALINORM 01/12 Appendix VIII. FAO/ WHO. 1999 (5).

Así dentro del grupo de productos lácteos, están los que se emplea para fabricar leche evaporada, yogurt, leches fermentadas, condensadas, cremas pasteurizadas, quesos. Otro grupo, el de aditivos para grasas, incluye los necesarios para aceites, grasas emulsionadas, mantequilla, margarina. Hay un grupo de aditivos para frutas frescas y para frutas procesadas. Otro, para vegetales frescos, procesados, fermentados, cocinados, fritos, nueces y semillas. Para alimentos como cocoa, imitación de chocolate, galletas suaves y fuertes. Así uno a uno se incluyen todos los alimentos con sus aditivos.

\section{ORIGEN DE LOS ADITIYOS ALIMENTARIOS. ¿NATURAL O ARTIFICIAL?}

Todos los aditivos, tal como lo son los alimentos, los animales y los vegetales son sustancias químicas y según su origen se les agrupa en: decantación, concentración, evaporación, sin modificar su estructura química.

Aditivos de origen natural, parcialmente modificados. La industria los obtiene aplicando los además procedimientos químicos y biológicos, como hidrólisis, acidificación, neutralización, fermentación. Mucho debe la industria alimentaria a la fermentación biotecnológica, que le permite transformar sencillas materias primas naturales almidón de maíz y de yuca, melaza de caña, en componentes del Ciclo de Krebs como fumarato para panadería, citrato para caramelos, mashmelos, bebidas; mayonesa, aconítico como flavorizante; aminoácidos como glutamato y diversos nucleótidos, sazonadores de uso mundial. Para ellos existe un conjunto de regulaciones muy severas. Para el glutamato monosódico GMS son emitidas por los miembros Reguladores IGIS del International Glutamate Information Service (6).

Aditivos no naturales, sintetizados en un laboratorio. Con equipos sensibles como cromatógrafo a gas, se identifican estructuras químicas de sustancias naturales que luego se sintetizan en otras iguales. Los aditivos sintetizados son el mayor número de aditivos, idénticos a los naturales que ni las enzimas del organismo humano pueden diferenciarlos de aquellos, metabolizándolos como tales.

\section{ATOMOS Y ESTRUCTURAS QUÍMICAS QUE POSEEN LOS ADITIVOS SINTETIZADOS}

Revisando el completo tratado sobre Food Chemistry 3th Ed. de Owen Fennema (7) en su capítulo 12 de Aditivos Alimentarios, se muestra los varios metales y no metales que son aditivos generalmente como sales de ácidos orgánicos, óxidos, hidróxidos, entre otras moléculas, como se observa a continuación. 
- Metales más utilizados: $\mathrm{Na}, \mathrm{K}$ y Ca, siguen Mg, $\mathrm{Fe}$, Mg y catión $\mathrm{NH} 4+$

- No metales: en primer lugar $\mathrm{C}, \mathrm{H}, \mathrm{O}$ y $\mathrm{N}$, elementos organógenos y a partir de ellos se forman estructuras orgánicas iguales a otras naturales, aminoácidos, ácidos grasos, ácoidos del metabolismo, proteinas enzimas, carbohidratros simples azúcares y complejos como celulosa y almidón derivados de ambos.

- Se emplean otros no metales como los halógenos $\mathrm{Cl}$, Br y I y anfígenos P y S.

El Handbook of Food Additives, en su $2^{\text {da }}$ Edición, (8) muestra las estructuras químicas de los aditivos, en ellas tomando como muestra uno solo de los rubros, el de flavorizantes o aromatizantes se observa que se repiten cationes y aniones, así;

1.- Hay 21 sales con catión alilo y anión propionato, butirato, hexanoato, sorbato.

2.- Hay 14 sales con catión etilo y anión formiato, acetato, butirato, octanoato.

3.- Hay 11 sales con catión isoamil y anión butirato, acetato, isobutirato o hexanoato.

4.- Hay ácidos orgánicos monocarboxilicos de $1 \mathrm{C}$, el fórmico; de $2 \mathrm{C}$, acético, de $3 \mathrm{C}$, propiónico, de $4 \mathrm{C}$ butírico, de $5 \mathrm{C}$ valérico, de $6 \mathrm{C}$ caproico, de $11 \mathrm{C}$ undecanoico.

5.- Hay ácidos orgánicos con características adicionales como poseer hidroxilos, dos o tres carboxilos, enlaces dobles, etc. Son ácido adípico, sórbico, tartárico, cetobutírico, levulínico, fumárico, málico, cítrico, mercaptopropiónico, cinámico. Más sus sales.

6.- Hay ácidos orgánicos grasos, láurico, mirístico, palmítico, esteárico, oleico.

7.- Hay más de 50 aditivos que son sales de los anteriores y derivados de ellas, acetato, propionato, butirato, valerato con cationes aromáticos, geranil, citronelil, neril, rodinil

8.- Hay alcoholes, 2 pentanol, 3 hexanol, 2 heptanol, 2 octanol, 2 nonanol, 3 decanol, 3 metil 2 butanol, o-cresol, phenol, 3 fenill propanol. y aldehidas o sus derivados como 3 metiltiobutanal, metiltiohexanal

9.-Los radicales metil, etil, propil, butil, isobutil, dimetil, acetil, etoxil, propil 2 metil, estructuras abiertas o ciclicas, que otorgan color, aromas, suavidad, $\mathrm{pH}$.

10.-También son aditivos alimentarios el eugenol, fármaco para aliviar dolor de muelas, resina de guayacol para la tos, ingredientes de preparaciones culinarias, sustancias de uso práctico, como sales de alumnio, sulfato de quinina, bentonita, parafina, ácido ascórbico o Vit. $\mathrm{C}$, aceite de castor, talco, cera de carnauba, glicerina, amaranto, caramelo, carotenos, chocolate, licopeno, riboflavina o Vit. B2, carragenatos, goma arábiga, lecitina, almidón.

\section{¿QUÉ OCURRE CON LOS ADITIVOS AL. SER CONSUMIDOS COMO PARTE DE LOS ALIMENTOS?}

Resultados muy diferentes según su estructura química, pudiéndose clasificar en:

De estructura química muy simple." Alcoholes, ácidos, sales, aminoácidos, aldehidas, cetonas, etc. Son la mayoria de aditivos y atraviesan con facilidad la vellosidad intestinal y ya en la sangre se confunden con moléculas iguales derivadas de los alimentos, siendo metabolizados como ellas.

De estructura química más complejas.-Como carbohidratos no digeribles, gomas diversas, carragenatos, pectinas. No atraviesan la vellosidad ni llegan a la sangre, no son metabolizados. Siguen la vía gástrica siendo eliminados con las heces.

De estructuras especiales.- Absorbidos pero no utilizados por el organismo. Atraviesan la vellosidad pero no son aprovechados por ninguna célula humana, son consideradas como desechos y el riñón los elimina por la orina.

\section{INOCUIDAD DE LOS ADITIVOS}

Garantizada por la constante evaluación toxicológica del JECFA, Comité Mixto FAO/OMS de Expertos en Aditivos Alimentarios y los Grupos Ad hoc, que aplican exigentes criterios para los aditivos y sus metabolitos, constituyentes normales en el organismo. Se enfatiza en aquellos de alimentos para niños, diabéticos, embarazadas y madres lactantes, deben estar declarados en el rotulado o etiquetado de los alimentos que los contienen, según el Comité del Codex sobre etiquetado de Alimentos $29^{\mathrm{a}}$ Sesión (9)

El trabajo de JECFA comprende ensayos sobre metodología de fabricación, presencia de impurezas, niveles de empleo en los alimentos y estimación 
de IDA, Ingestión Diaria Aceptable. Sólo se excluyen de dicha regulación las sustancias GRAS, Generalmente Reconocidas como Seguras, iniciales de Generally Recognized As Safe. Son GRAS sal, azúcar, vinagre, goma-guạr, especias, vitaminas, glutamato monosódic entré otros.

\section{REFERENCIAS BIBLIOGRAFIACAS}

1.- John M.deMan. 2003. Principles of Food Chemistry, 3rd. Edition, AN Aspen Publication.

2.- JECFA. 1992. Comité Mixto FAO/OMS, de Expertos en Aditivos Alimentarios, Codex Alimentarius, Volume 1.

3.- Downham A. and Collins P. 2000. Colouring our foods in the Last and Next Millenium, International Journal of Food Science and Technology, No 35, pp. 5-22.
4.- FAO-WHO. 1999. Norma General del Codex para Aditivos Alimentarios, volumen $1 \mathrm{~A}$.

5.- ALINORM 01/12, Appendix VIII de la FAO/ WHO, 1999.

6.- IGIS Members Regulations, International Glutamate Information Service Members. 2003. Australia,Brazil, Canada, China, Europe, Japan, Russian Federation,Switzerland, Turkey, USA.

7.- Fennema O. 1996, Food Chemistry, Third Edition, Ed.Marcel Dekker,Inc.

8.-Handbook of Food Additives. 2002. $2^{\text {nd }}$ Ed., Synapse Information Resources.

9.- Comité Codex sobre Etiquetado de Alimentos. 2001. 29a Sesión, Ottawa Canada, pp.1-4, mayo. 